\title{
PELATIHAN DAN PEMBEKALAN INSTALASI AC SPLIT SISWA SMKN-1 CIPATAT KABUPATEN BANDUNG BARAT
}

\author{
Triaji Pangripto ${ }^{1}$, Sumeru ${ }^{1}$, Tandi Sutandi ${ }^{1}$, Apip Badarudin ${ }^{1}$, Andriyanto $\mathrm{S}^{1}$, Markus ${ }^{1}$, \\ AP Edi Sukamto ${ }^{1}$ \\ Jurusan Teknik Refrigerasi dan Tata Udara, Politeknik Negeri Bandung \\ Email: ${ }^{1}$ triajipangripto@polban.ac.id,
}

\begin{abstract}
Abstrak
SMKN1 Cipatat berlokasi di Wilayah Kabupaten Bandung Barat yang berdekatan dengan dengan Tempat pembuangan akhir sampah Kerta Mukti, sehingga para siswa banyak yang berasal dari keluarga ekonomi kurang mampu karena mata pencaharian orang tua mereka adalah mengandalkan dari sampah. Para lulusan SMK Jurusan otomotif pada umumnya hanya mampu atau terampil mengerjakan persoalan yang berkaitan dengan bidang mesin otomotifnya saja, itupun tergantung pada sarana praktikumnya yang masih belum memadai jumlahnya untuk melayani semua siswa. Ada keinginan dari mitra untuk menambah wawasan bagi para siswa sebagai bekal keahlian tambahan setelah lulus dan salah satu pilihanya adalah tentang keahlian di bidang A/C Split. Sampai saat ini SMKN 1 Cipatat belum memiliki sarana praktikum berupa sebuah training unit A/C Split yang representatif untuk dapat digunakan sebagai sarana praktikum. Hal tersebut dapat menyebabkan para lulusan SMK menjadi kurang terampil dan kurang kompetitif untuk menghadapi peluang kesempatan kerja yang tersedia di lapangan. Dengan adanya peningkatan kompetensi di bidang A/C Split maka pengetahuan dan ketrampilan para siswa SMKN 1 jurusan otomotif tersebut menjadi bertambah dan diharapkan dapat menguasai dalam hal memasang, memvakum dan mengisi refrigeran/freon serta memperbaiki mesin A/C split dengan benar Metode yang dilakukan adalah dengan menyediakan satu buah training unit A/C Split berikut peralatan servicenya, selanjutnya para siswa akan mengikuti pembekalan dan pelatihan sesuai dengan modul-modul yang disediakan dan dirancang secara sederhana sehingga mudah dipraktikkan oleh para siswa. Program peningkatan kompetensi ini diharapkan pula diikuti oleh guru pengampu pelajaran otomotif sehingga program pembekalan dan pelatihan di bidang A/C split ini dapat dilanjutkan untuk dapat diberikan kepada para siswa angkatan berikutnya Dengan adanya kegiatan peningkatan kompetensi di bidang teknik A/C split bagi para siswa SMKN1 Cipatat maka para lulusannya diharapkan memiliki ilmu pengetahuan tambahan di bidang A/C split sebagai nilai tambah untuk dapat bersaing dalam mendapatkan pekerjaan atau dapat pula digunakan sebagai bekal untuk berwirausaha di bidang service A/C split.
\end{abstract}

Kata kunci: Pelatihan, pemasangan A/C, A/C split, SMKN 1 Cipatat PENDAHULUAN

SMK Negeri berdiri sejak tahun 2015 dengan Bidang Studi Keahlian diantara- 
DIFUSI

Volume 3, No.1 Januari 2020

nya Bisnis Manajemen, Teknologi dan Rekayasa, Teknologi Informasi dan Komunikasi serta Teknologi dan Rekayasa. Sementara Program Studi Keahlian yang dimiliki diantaranya: Administrasi, Otomotif, Teknik Komputer dan Informatika serta Teknik Ketenagalistrikan, dengan Kompetensi Keahlian antara lain: Otomatisasi Tata Kelola Perkantoran, Teknik Kendaraan Ringan Otomotif, Multimedia serta Teknik Instalasi Tenaga Listrik.

Berdasarkan data jumlah siswa yang terdaftar di Jurusan Teknik Kendaraan Ringan Otomotif SMK Negeri 1 Cipatat pada saat ini tercatat sebanyak 83 siswa dengan jumlah guru sebanyak 3 orang. Jumlah siswa tersebut merupakan potensi sumber daya manusia yang cukup banyak dalam menyongsong dunia kerja tingkat menengah di bidang engineering khususnya otomotif. Seiring dengan pertumbuhan ekonomi masyarakat saat ini menunjukkan jumlah pemilik kendaraan otomotif semakin meningkat dengan tuntutan kenyamanan saat berkendaraan. Menurut data samsat jumlah kendaraan jenis sedan, jeep dan minibus yang berada di kota dan kabupaten Bandung saja sebanyak sekitar 950.000 unit. Kondisi tersebut adalah peluang bagi lulusan SMK untuk mendapatkan pekerjaan atau membuka usaha sendiri di bidang service atau pebaikan.

Para siswa SMK Negeri 1 Cipatat pada dasarnya telah memperoleh pelajaran teori dan praktik di bidang teknik otomotif, namun terdapat beberapa masalah diantaranya sarana penunjang untuk praktikumnya masih kurang memadai karena jumlahnya yang masih belum mencukupi sehingga perlu ditambah. Kondisi peralatan praktikum yang ada saat ini masih dapat dikatakan belum representatif karena belum memiliki satu buahpun kendaraan yang dapat dioperasikan sebagai sarana praktikum yang mewakili sebagai alat praktikum yng sesungguhnya yaitu sebuah kendaraan yang dapat dioperasikan.

Guru pengampu yang ada saat ini berjumlah 3 orang dengan kompetensi khusus di bidang otomotif. Ada keinginan yang kuat dari mitra untuk meningkatkan komptensi siswanya dengan memberikan pembekalan pengetahuan selain hanya di bidang otomtif juga sekalian di bidang $\mathrm{A} / \mathrm{C}$ rumah tangga dan $\mathrm{A} / \mathrm{C}$ mobilnya. Harapannya para lulusan SMKN 1 Cipatat jurusan otomtif kendaraan ringan akan memiliki nilai lebih di bandingkan lulusan SMK lain yang sejenis dan kemampuan lulusan dalam menguasai di bidang $\mathrm{A} / \mathrm{C}$ Rumah tangga dan $\mathrm{A} / \mathrm{C}$ mobil akan menjadi nilai tambah bagi pengguna lulusan SMKN 1 Cipatat.

Untuk dapat mewujudkan keinginan mitra tersebut maka solusi yang ditawarkan adalah diberikan satu buah training unit $\mathrm{A} / \mathrm{C}$ rumah tangga (A/C Split) terlebih dahulu yang dilengkapi dengan modul-modul praktis yang sangat mudah untuk dipraktikan oleh para siswa dan guru SMKN 1 Cipatat. Peningkatan kompetensi di bidang A/C Split bagi para siswa jurusan otomotif kendaraan ringan dan guru pengampu ini diberikan dalam bentuk teori dan praktik lansung di lingkungan SMKN 1 Cipatat. Training unit yang disediakan berupa sebuah Panel hardboard yang dapat digunakan untuk latihan instalasi dan dapat dipasangi Unit A/C Split serta dilengkapi 
DIFUSI

Volume 3, No.1 Januari 2020

dengan peralatan service dan peralatan penunjang lainya.

Karena materi pelajaran otomotif sudah merupakan program utama dari SMKN1 Jurusan kendaraan ringan otomotif maka pembekalan dan pelatihan akan lebih difokuskan pada materi A/C Split sebagai bekal tambahan ilmu pengetahuan untuk menyongsong peluang kerja setelah lulus dari SMK sehingga diharapkan para lulusan SMKN1 Cipatat akan memiliki ketrampilan yang lebih dari sekedar menguasai bidang otomotifnya saja namun dapat pula mengoperasikan dan memperbaiki A/C Split. Dengan demikian maka peluang para lulusan untuk mendapatkan pekerjaan atau berwirausaha di bidang $\mathrm{A} / \mathrm{C}$ Split (A/C Rumah Tangga) menjadi lebih terbuka.

Kebutuhan pengkondisi udara $(\mathrm{A} / \mathrm{C}) \mathrm{di}$ Indonesia saat ini mencapai 2,5 juta unit per tahun. Diperkirakan pertumbuhan permintaan $\mathrm{A} / \mathrm{C}$ sekitar $6 \%-10 \%$ per tahun. Dengan tingginya permintaan kebutuhan $\mathrm{A} / \mathrm{C}$ di Indonesia maka dapat membuka peluang kerja dalam bidang $\mathrm{A} / \mathrm{C}$. Saat ini para teknisi A/C yang ada di lapangan pada umumnya belum dibekali pengetahuan dasar tentang prisip kerja $\mathrm{A} / \mathrm{C}$ secara benar, sehingga dalam pemasangan maupun perbaikan lebih sering melakukan "trial and error". Sehingga tingkat kebocoran freon dari $\mathrm{A} / \mathrm{C}$ semakin meningkat dari tahun ke tahun.

Dari sisi energi, A/C pada perumahan maupun gedung mengkonsumsi energi $50 \%$ sampai $70 \%$ dari energi total. Artinya, bila kinerja $\mathrm{A} / \mathrm{C}$ yang terpasang dalam kondisi prima, maka konsumsi hanya mencapai $50 \%$ dari konsumsi energi listrik total. Namun sebaliknya, bila kinerja $\mathrm{A} / \mathrm{C}$ kurang optimal, maka konsumsi energi listrik dapat mencapai $70 \%$. Kinerja AC dipengaruhi oleh refrigeran (freon) yang digunakan dan pemasangan $\mathrm{A} / \mathrm{C}$. Pemasangan $\mathrm{A} / \mathrm{C}$ yang baik dan benar selain akan mengurangi tingkat kerusakan juga menjamin kenyamanan konsumen.

A/C Split adalah jenis alat pengkondisi udara yang dapat dikelompokan sebagai unitary air conditioner (A/C unitary) yaitu sebuah unit mesin $\mathrm{A} / \mathrm{C}$ denga kapasitas yang relatif kecil dan bisa dipasang secara mudah. Jenis unitary umumnya digunakan pada perumahan maupun gedung-gedung yang tidak terlalu besar. Pada jenis ini, instalasi dan pengontrolan temperatur tiap ruangan tidak tergantung pada ruangan lain.

Jenis $\mathrm{A} / \mathrm{C}$ split adalah jenis $\mathrm{A} / \mathrm{C}$ Unitary yang paling banyak digunakan karena sangat mudah saat diinstalasi dan diperbaiki, penempatanyapun dapat disesuaikan dengan kondisi di lapangan yaitu dapat dipasang di atas lantai atau menempel di dinding dengan bantuan dudukan berupa bracket. Gambar 1 menunjukkan $\mathrm{A} / \mathrm{C}$ split yang banyak dipasang di gedung komersial dan perkantoran. Terdapat dua bagian utama pada $\mathrm{A} / \mathrm{C}$ split, yaitu indoor unit dan outdoor unit. Indoor unit diletakkan di dalam ruangan sedangkan outdoor unit ditaruh di bagian luar ruangan. 


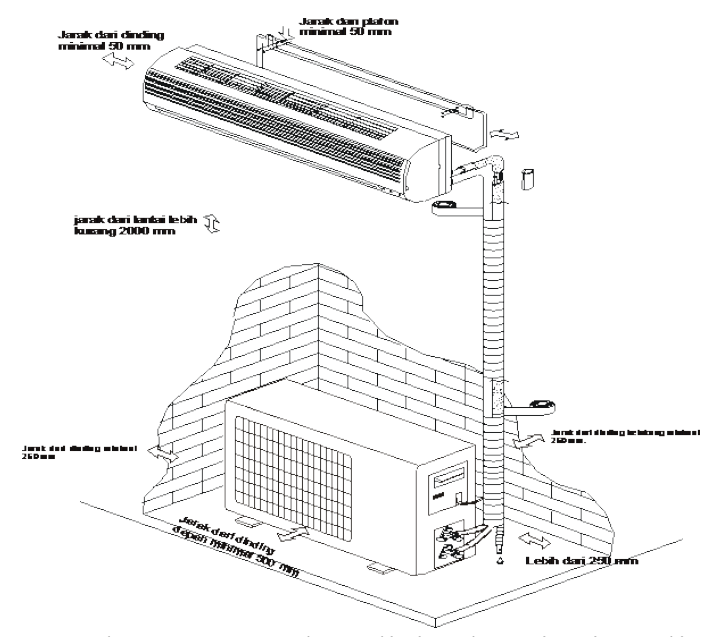

Gambar 1. Pengkondisi udara jenis split yang banyak digunakan pada gedung komersial dan perkantoran

Berkaitan dengan sistem pengkondisi udara maka tidak dapat dilepaskan dari fluida yang diisikan ke dalam sistem $\mathrm{A} / \mathrm{C}$ tersebut. Fluida yang diisikan ke dalam sistem unit $\mathrm{A} / \mathrm{C}$ dikenal dengan nama Refrigeran (orang awam sering menyebutnya freon). Pada akhir-akhir ini sudah sangat sering dibicarakan dan dibahas tentang pengaruh refrigeran tersebut yang dapat merusak lingkungan terkait dengan isue bocornya lapisan ozone atau efek rumah kaca yaitu potensi meningkatnya temperatur permukaan bumi (GWP = Global Warming Potential). Jenis refrigeran yang pada saat ini banyak diproduksi adalah jenis refrigeran yang lebih ramah lingkungan atau yang memiliki potensial kecil terhadap kemampuanya dapat merusak lingkungan.

Fungsi utama dari refrigeran adalah untuk menyerap kalor dari ruangan yang dikondisikan dan membuang kalor ke lingkungan. Penyerapan kalor terjadi di evaporator dan pembuangan kalor terjadi di kondenser. Sebelum diketahui dampak negatif dari refrigeran pada lingkungan, yaitu efek rumah kaca dan perusakan lapisan ozone, jenis refrigeran yang banyak digunakan adalah R11 dan R12 [1].

Namun pada tahun 1970-an ditemukan oleh para ahli bahwa freon-freon sintetik (CFC) dapat menimbulkan dampak negatif pada lingkungan, yaitu perusakan ozon (ODP = ozone depletion potential) dan pemanasan global $(\mathrm{GWP}=$ global warming potential) $[2,3]$. Sifat berbagai refrigeran pada lingkungan terlihat pada Tabel 1.

Tabel 1. Sifat berbagai refrigeran pada lingkungan

\begin{tabular}{clcc}
\hline No & Refrigeran & ODP* & GWP* \\
\hline 1. & R12 & 0,82 & 10.600 \\
2. & R22 & 0,034 & 1.810 \\
3. & R410A & 0 & 2.088 \\
4. & R404A & 0 & 3.920 \\
5. & R407C & 0 & 1.610 \\
6. & R32 & 0 & 675 \\
7. & R290 & 0 & 3 \\
& (propana) & & \\
\hline
\end{tabular}

Pada Tabel 1 terlihat bahwa R12 (CFC) memiliki sifat ODP dan GWP yang paling besar dibandingkan dengan refrigeran lainnya. Sehingga penggunaan freon jenis ini telah dilarang pada beberapa tahun yang lalu dan sebagai penggantinya adalah R22 (HCFC) [3,4]. Namun karena R22 masih memiliki sifat ODP dan GWP yang masih tinggi maka dalam waktu dekat harus diganti dengan freon dari keluarga HFC (R410A, R404A, R407C dan R32) yang tidak memiliki sifat ODP [3-5]. Saat ini di Indonesia mulai banyak digunakan R32 sebagai refrigeran $\mathrm{A} / \mathrm{C}$ jenis split. Refrigeran jenis ini memiliki ODP nol dan nilai GWP yang rendah, yaitu 675 [6].

\section{METODE}


DIFUSI

Volume 3, No.1 Januari 2020

Pelatihan ini diikuti oleh 24 siswa dan satu orang teknisi dari Jurusan Teknik Otomotif dan satu orang Teknisi. Pelatihan dilaksanakan di SMKN1 Cipatat. Meliputi materi Teori dan praktik. Metode yang dilakukan adalah setelah mitra menerima sebuah training unit $\mathrm{A} / \mathrm{C}$ Split beserta modul-modulnya, selanjutnya diberikan pembekalan dan pelatihan oleh pelaksana dengan konsep Learning by Doing, dimana setiap siswa akan mendapatkan penjelasan yang relatif lengkap namun sederhana dan mudah dipahami untuk level pendidikan SMK. Setiap peserta diwajibkan untuk mencoba melakukan kegiatan praktik menginstalasi; memvakum dan mengisi refrigeran sesuai dengan panduan yang diberikan pada modul. Para guru akan mendapatkan penjelasan penggunaan modul-modul tersebut dan diberikan pula kesempatan untuk melakukan praktikum dengan bimbingan khusus sehingga diharapkan akan mampu menjelaskan kelak kepada para siswanya. Monitoring dan komunikasi dengan mitra akan dijaga untuk keberlangsungan dan kelancaran dalam proses belajar mengajar di SMKN 1 Cipatat khususnya yang berkaitan dengan materi A/C Split.

Kegiatan pembekalan dan pelatihan dilaksanakan di dalam kelas dan di laboratorium SMKN 1 Cipatat dengan peralatan yang telah disediakan berupa satu buah training unit berikut peralatan pendukungnya. Materi pembekalan dan pelatihan disiapkan oleh pemateri berupa modul teori dan praktik. Jumlah peserta pada pembekalan dan pelatihan pada sesi teori ini adalah 24 (dua puluh empat) orang sementara untuk sesi praktikum dilakukan secara bergiliran dengan jum- lah per kelompok 4 (empat) orang dan untuk sementara siswa yang lainnya akan mendapat kesempatan secara bergiliran.

Bentuk kegiatan yang dilakukan pada pembekalan/pelatihan ini ada dua tahap, yaitu teori dan praktik. Teori disampaikan selama kurang lebih 4 jam $(0,5$ hari), meliputi:

a. prinsip kerja sistem $\mathrm{A} / \mathrm{C}$ split,

b. komponen-komponen $\mathrm{A} / \mathrm{C}$ split,

c. definisi kinerja $\mathrm{A} / \mathrm{C}$ split,

d. cara menggunakan peralatan service,

e. cara mengisi refrigeran yang tepat dan benar, dan

f. cara mendeteksi kerusakan atau troubleshooting dan perbaikanya

Praktik disampaikan selama kurang lebih 1-2 hari meliputi:

a. brazing (penyambungan) pipa tembaga,

b. proses pengerjaan pemipaan sistem $\mathrm{A} / \mathrm{C}$ split,

c. pemvacuman dan pengisian refrigeran,

d. pengukuran temperatur dan tekanan untuk mengamati kinerja $\mathrm{A} / \mathrm{C}$, dan

e. perawatan dan perbaikan $\mathrm{A} / \mathrm{C}$ split.

Gambar 2 menunjukkan foto bersama kepala sekolah SMKN1 Cipatat saat dilakukan pembukaan acara pelatihan dan pembekalan A/C Split.

Setelah acara pembukaan selesai maka kegiatan dilanjutkan dengan pemberian materi teori sistem refrigerasi sederhana di dalam kelas. Materi teori disampaikan selama sekitar 4 jam (dari jam 9.00 sampai 14.00 WIB). Gambar 3 adalah suasana peserta saat mengikuti paparan 
materi teori dasar sistem pendingin $\mathrm{A} / \mathrm{C}$ Split.

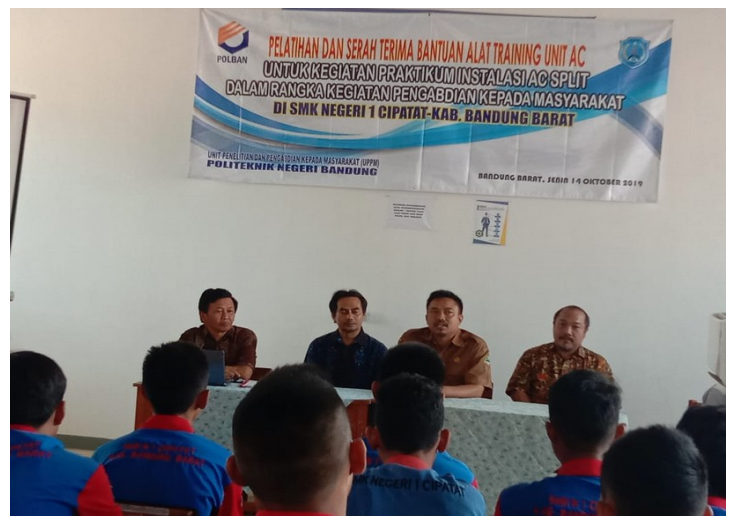

Gambar 2. Sambutan dan Pembukaan Acara Pelatihan dan Pembekalan A/C Split.

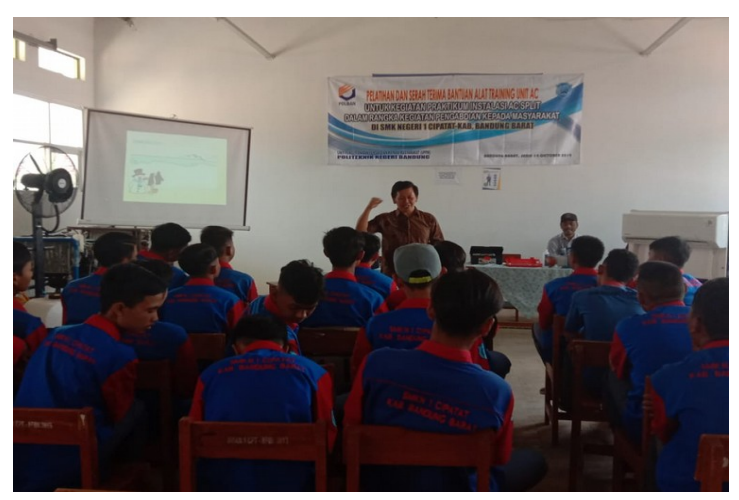

Gambar 3. Peserta sedang mendapatkan materi Teori dasar AC split

Metoda pemberian materi teori diberikan lebih banyak dengan cara interaktif tanya jawab antara peserta dengan pemateri dengan suasana yang dikondisikan relatif santai tetapi tetap fokus agar para siswa sebagai peserta dapat memahami materi yang disampaikan dengan baik. Metode ini dipilih dengan harapan peserta pelatihan menjadi tertarik dan tidak takut untuk bertanya atau menyampaikan sesuatu yang belum dipahaminya.
Kegiatan pelatihan praktik diberikan sesuai dengan standar prosedur seperti layaknya yang biasa dilakukan oleh para teknisi A/C yang bekerja di perusahaan yaitu meliputi : cara pengoperasian sistem $\mathrm{A} / \mathrm{C}$ split, metode penyambungan pipa, cara menggunakan alat ukur, cara pemvakuman sistem sebelum proses pengisian refrigeran, cara pengisian refrigeran yang benar dan cara instalasi $\mathrm{A} / \mathrm{C}$ split yang baik dan benar.

Cara mengoperasikan mesin $\mathrm{A} / \mathrm{C}$ relatif sangat mudah yaitu setelah power supply dihubungkan ke jala-jala listrik maka dengan menekan tombol remote $\mathrm{A} / \mathrm{C}$ akan bekerja dan langkah selanjutnya adalah menyetel temperatur ruangan nyaman untuk manusia adalah sekitar $23^{\circ} \mathrm{C}$ dengan kelembaban sekitar $65 \%$ hingga 70\%. Gambar 4 menunjukkan peserta pelatihan sedang mencoba melakukan latihan penyambungan pipa dengan metoda brasing. Penyambungan pipa adalah bagian yang tidak dapat dipisahkan dari kegiatan service $\mathrm{A} / \mathrm{C}$ split karena hampir semua unit mesin $\mathrm{A} / \mathrm{C}$ selalu menggunakan pipa tembaga sebagai saluran fluida refrigerannya. Keahlian menyambung pipa sangat diperlukan manakala sistem mengalami kebocoran.

Setelah proses brasing biasanya diikuti dengan langkah berikutnya yaitu mengecek kebocoran pada hasil brasing tersebut. Dalam sistem tata udara tidak boleh terdapat kebocoran walau sekecil apapun, karena kebocoran akan menyebabkan isi refrigeran habis keluar dari sistem dan mesin $\mathrm{A} / \mathrm{C}$ menjadi tidak dingin. 


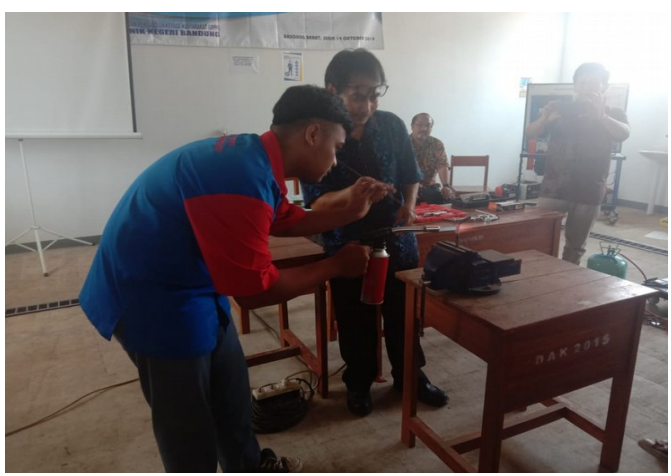

Gambar 4. Peserta sedang latihan praktik menyambung pipa tembaga dengan metoda brasing

Langkah yang tidak kalah pentingnya dalam hal menangani sistem tata udara A/C split adalah proses pemvakuman sebelum sistem diisi dengan refrigeran maka perlu divakum terlebih dahulu dengan tujuan untuk membuang noncondensable gas yang dapat merugikan sistem saat beroperasi. Apabila langkah pemvakuman telah dilaksanakan maka langkah pengisian refrigeran dapat dilakukan dengan memperhatikan aspek kecukupan jumlah refrigeran yang diisikan, diantaranya: massa refrigeran yang diisikan harus sesuai dengan jumlah yang direkomendasikan pada Name-plate, arus listrik yang terukur tidak melebihi dari yang ditulis pada Name-plate dan tentunya temperatur evaporator dapat tercapai /dingin. Gambar 5 menunjukkan peserta sedang diberikan penjelasan dan diberi kesempatan untuk melakukan proses pengisian refrigeran pada mesin $\mathrm{A} / \mathrm{C}$ split.

Penggunaan alat ukur yang benar seringkali menjadi kendala bagi sebagian orang khususnya bagi para teknisi lapangan yang masih memiliki keterbatasan pengetahuan, oleh karena itu para peserta siswa SMKN1 perlu dibekali pe- ngetahuan cara menggunakan dan membaca alat ukur dengan benar khususnya alat ukur yang biasa digunakan di bidang teknik tata udara, seperti; manifold gauge, tang amper/multi meter, dan thermometer.

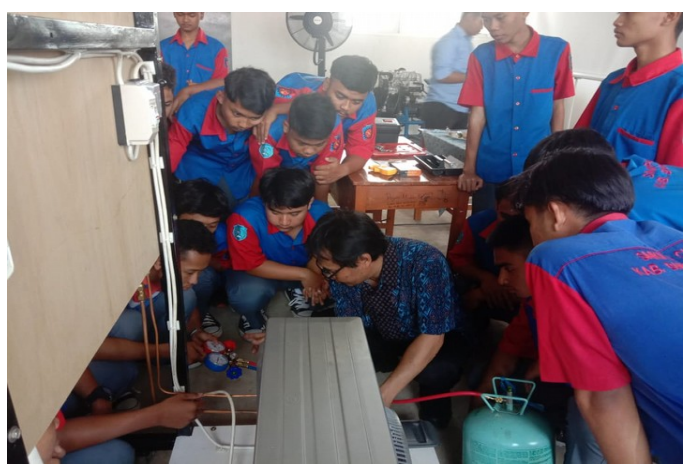

Gambar 5 Para peserta sedang mengisi refrigeran.

Peserta diberi kesempatan untuk memasang alat ukur tersebut pada sistem dan diminta untuk membacanya secara benar. Gambar 6 menunjukkan peserta sedang mendapatkan penjelasan saat melakukan pengamatan cara menggunakan dan membaca alat ukur manifold gauge pada mesin $\mathrm{A} / \mathrm{C}$ split.

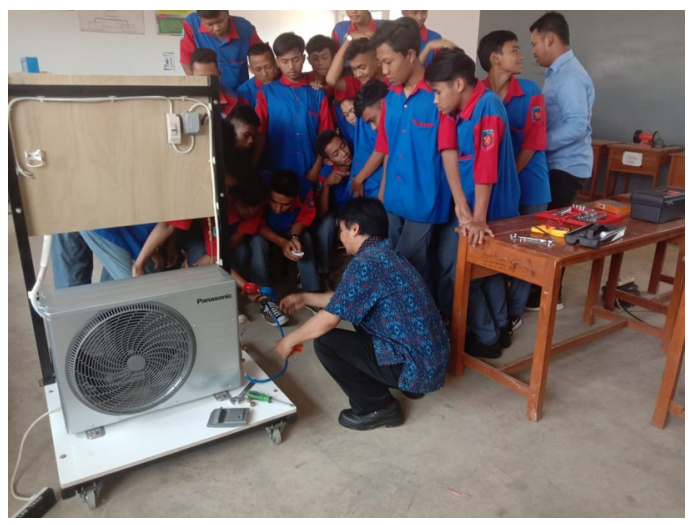

Gambar 6. Peserta sedang

Menggunakan Alat Ukur Manifold-

Gauge.

Manifold gauge adalah alat ukur tekanan yang sering digunakan untuk menge- 
DIFUSI

Volume 3, No.1 Januari 2020

tahui besarnya tekanan kerja pada mesin $\mathrm{A} / \mathrm{C}$ tersebut. Dengan memahami cara pengguanaan maka seorang teknisi dapat memprediksi kondisi mesin $\mathrm{A} / \mathrm{C}$ tersebut apakah dalam keadaan baik atau bermasalah.

\section{HASIL DAN PEMBAHASAN}

Tujuan utama dari pelatihan ini adalah untuk menghasilkan lulusan SMKN 1 yang memilki pengetahuan tambahan di bidang A/C Split sebagai bekal dalam kompetisi menyongsong dunia kerja atau sebagai bekal bagi yang berminat berwirausaha di bidang service mesin A/C split.

Para peserta dengan jumlah sebanyak 24 orang siswa pada umumnya sangat antusias saat mengikuti pelatihan karena menurut mereka pengetahuan tentang sistem tata udara khususnya $\mathrm{A} / \mathrm{C}$ split dirasa tidak terlalu sulit untuk dipelajari. Hal tersebut tentu terasa relatif mudah karena metoda dan materi yang disampaikan bersifat langsung merupakan problem solving. Kegiatan pelatihan dan pembekalan ini diikuti pula oleh guru dan teknisi walaupun secara tidak langsung. Namun demikian harapan dari pelaksana dengan adanya keterlibatan guru akan dapat membantu siswa manakala ada beberapa hal yang mungkin ingin ditanyakan oleh peserta didik setelah sekian lama pelaksanaan pelatihan selesai. Seorang yang memiliki keahlian dalam melayani/service di bidang tata udara seperti $\mathrm{A} / \mathrm{C}$ split pada umumnya akan mendapatkan peluang kerja tambahan lainnya di bidang yang masih beririsan seperti: service kulkas atau service $\mathrm{A} / \mathrm{C}$ jenis Cassete. Hal ini sangat memung- kinkan karena ilmu pengetahuan dan ketrampilan yang diperlukan relatif tidak jauh berbeda, demikian pula peralatan yang digunakan pun sama. Dengan demikian harapan yang ingin dicapai dari pelatihan dan pembekalan ini adalah membantu para lulusan tenaga teknisi menengah untuk mendapatkan peluang kerja atau berwirausaha secara mandiri atau secara berkelompok dalam bidang keahlian yang lebih luas lagi.

Peluang kerja di bidang teknik tata udara $\mathrm{A} / \mathrm{C}$ split masih sangat terbuka luas seiring dengan pembangunan sarana dan prasarana daerah maupun nasional yang cukup berkembang dengan pesat, seperti pendirian hotel-hotel bertingkat, pendirian pusat perbelanjaan/mall, dan tuntutan sebagian masyarakat akan standar kehidupan yang lebih baik dan nyaman. Tentunya dengan kondisi tersebut keperluan akan alat penyejuk ruangan seperti $\mathrm{A} / \mathrm{C}$ atau mesin pendingin untuk menyimpan produk makanan akan semakin meningkat, yang artinya akan memerlukan pula tenaga ahli atau terlatih yang mampu melayani service di bidang tersebut. Pada saat yang bersamaan lulusan SMKN yang telah dibekali pengetahuan dan ketrampilan di bidang tata udara $(\mathrm{A} / \mathrm{C})$ diharapkan dapat memanfaatkan peluang tersebut sebagai tempat tujuan bekerja dan mengembangkan kariernya.

\section{KESIMPULAN}

Jumlah peserta pelatihan terdiri dari siswa jurusan otomtif yang pada awalnya kurang mengenal tentang mesin tata udara dan setelah dilakukan pembekalan tentang $\mathrm{A} / \mathrm{C}$ split meliputi teori dan 
DIFUSI

Volume 3, No.1 Januari 2020

praktik pada umumnya merasa ingin mendalami dan mempelajari lebih detail lagi terutama setelah mereka mengetahui bahwa konsep sistem tata udara $\mathrm{A} / \mathrm{C}$ split ternyata tidak jauh berbeda dengan konsep pada sistem A/C Mobil. Peserta berharap selanjutnya diberi pembekalan tentang $\mathrm{A} / \mathrm{C}$ mobil agar lebih beririsan dengan jurusan yang sedang dipelajari di sekolah. Berdasarkan pengujian lisan dan pengamatan saat praktik, peserta dapat melakukan pemasangan, pemvakuman dan pengisisan refrigeran pada $\mathrm{A} / \mathrm{C}$ split dengan cukup baik dan benar.

Saran yang dapat disampaikan adalah: walaupun pada saat pelatihan peserta didik dapat melakukan kegiatan dasar penanganan pada sistem tata udara $\mathrm{A} / \mathrm{C}$ split, namun tetap diperlukan penyegaran secara berkala agar pengetahuan tentang $\mathrm{A} / \mathrm{C}$ split yang telah diperoleh tidak hilang atau berkurang. Caranya bisa saja materi pengatahuan tantang $\mathrm{A} / \mathrm{C}$ split tersebut menjadi kegiatan LKS di sekolah.

\section{UCAPAN TERIMAKASIH}

Pelatihan ini terselenggara berkat Dana DIPA Politeknik Negeri Bandung melalui skema Pengabdian Kepada Masyarakat dengan Surat Perjanjian Pelaksanaan Kegiatan No: 379.2/PL1.R7/PM/2019. freezer performance. Applied Mechanics and Materials. 819, pp. 231-235, 2016.

[2] I. Wellid, K. Sumeru, A. A. Aziz, H. Nasution dan A. M. Abioye. Performance analysis of hydrocarbon mixture to replace $R 134 a$ in an automotive air conditioning system. Applied Mechanics and Materials. 554, pp. 444-448, 2014.

[3] G. Lorentzen, The use of natural refrigerants: a complete solution to the $\mathrm{CFC} / \mathrm{HCFC}$ predicament. International Journal of Refrigeration. 18: pp. 190-197, 1995.

[4] S. Devotta, A. S., Padalkar, dan N. K. Sane, Performance assessment of HC-290 as drop-in substitute to HCFC-22 in a window air conditioner. International Journal of Refrigeration. 28, pp. 594-604. 2005.

[5] G. Zhou dan Y. Zhang, Performance of a split-type air conditioner matched with coiled adiabatic capillary tubes using HCFC22 and HC290. Applied Energy. 87: pp.1522-1528, 2010.

[6] W. Guo, G. Ji, H., Zhan, dan D. Wang, R32 compressor for air conditioning applications in China. Proceeding of International Compressor Engineering Conference, Purdue University, Paper 2098, 2012.

\section{REFERENSI}

[1] T. Sutandi, K. Sumeru, H. Nasution, dan F. N. Ani, Evaluation of the impact of refrigerant charge of $\mathrm{HC}-290$ to replace $\mathrm{HCFC}-22$ in a 